\title{
Removal of Berberine from Wastewater by MIL-101(Fe): Performance and Mechanism
}

\author{
Juan Li, Liangjie Wang, Yongqiang Liu, Ping Zeng,* Yan Wang, and Yizhang Zhang \\ Cite This: https://dx.doi.org/10.1021/acsomega.0c03422 \\ Read Online
}

ABSTRACT: The water contamination from pharmaceuticals and personal care products (PPCPs) has attracted worldwide attention in recent years because of its threat to public health. Berberine is a typical anti-inflammatory medicine and berberine wastewater is difficult to be treated due to its high toxicity, poor biodegradability, and high acidity. Metal-organic frameworks would be a good choice to remove berberine from wastewater due to its advantages of high specific surface area, ultrahigh porosity, and structural and functional tunability. In this study, MIL-101 $(\mathrm{Fe})$ was synthesized and used for the removal of berberine from water. Experimental results indicated that MIL-101(Fe) showed promising characteristics when berberine was adsorbed in acidic wastewater. The high concentration of chloride in berberine wastewater could promote the adsorption of berberine by MIL-101(Fe). Fitting of batch equilibrium data showed that MIL$101(\mathrm{Fe})$ had a maximum adsorption capacity of $163.93 \mathrm{mg} / \mathrm{g}$ for berberine

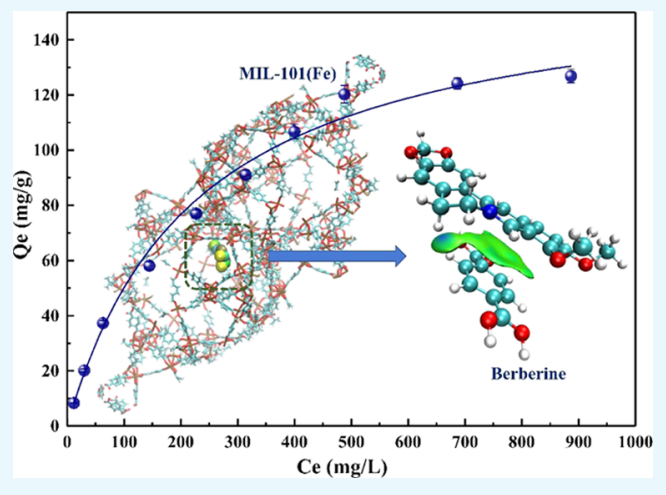
removal at $\mathrm{pH} 7$, and the berberine sorption on MIL-101(Fe) followed the pseudo-second-order model. Furthermore, the associate mechanism for berberine removal was proposed by characterizing the material and theoretical calculation. The X-ray power diffraction (XRD), Fourier transform infrared spectroscopy (FTIR), and X-ray photoelectron spectroscopy (XPS) analysis showed that no chemical reaction occurred during the adsorption of berberine by MIL-101(Fe). Also, the theoretical calculation results indicated that $\pi-\pi$ interactions may play the main role in the adsorption of berberine onto MIL-101(Fe). The findings of this study suggest that MIL-101(Fe) is a promising sorbent for berberine removal from wastewater.

\section{INTRODUCTION}

The contamination of water by pharmaceuticals and personal care products (PPCPs) has attracted worldwide attention in recent years because of its threat to public health. ${ }^{1}$ Berberine is an anti-inflammatory medicine with broad-spectrum antibiotic activity and pharmacological effects. ${ }^{2}$ Berberine can be used to treat cancer, diabetes, and liver disease, ${ }^{3}$ and the demand for berberine is increasing in recent years. ${ }^{4}$ Berberine is originally isolated from a variety of Chinese herbs, but nowadays it is mainly produced by chemical synthesis. ${ }^{5}$ During the chemical synthesis of berberine, a large amount of wastewater would be produced, which usually contains a high concentration of residual berberine. At present, the berberine wastewater is mainly discharged into the traditional sewage treatment plants directly for treatment. ${ }^{6}$ However, the conventional biological treatment system was usually inefficient for the treatment of berberine wastewater because it is usually highly acidic containing a high concentration of berberine and organics with antibacterial characteristics. ${ }^{3,5}$ Because of the adverse effects of berberine, ${ }^{7,8}$ efficient treatment methods are urgently needed to treat this berberine wastewater.

Many methods have been used for the removal of berberine, including Fenton oxidation, ${ }^{9}$ electrochemistry method, ${ }^{10}$ electrocoagulation, ${ }^{6}$ biodegradation, ${ }^{11}$ and adsorption method. ${ }^{12}$ Among these, the adsorption method is a promising technology for the removal of berberine from water due to its simple operation, high removal efficiency, and low cost. ${ }^{13}$ The adsorbents used for berberine removal mainly include mesoporous carbon, ${ }^{2,14}$ resin, ${ }^{3,15}$ and some minerals. ${ }^{16,17}$ However, because of the high acidity and complex composition of berberine wastewater, the capacities of these materials for berberine is usually low, which limits the application of these adsorbents in berberine wastewater treatment. Thus, it is necessary and important to develop efficient adsorbents for berberine removal.

Metal-organic frameworks (MOFs) are an emerging class of porous materials, which are constructed from metal ions and organic ligands. ${ }^{18}$ MOFs have the advantages of ultrahigh porosity, good chemical stability, high thermal stability, and tunable structure and function. ${ }^{19,20}$ Thus, the potential application of MOFs has gained more and more attention from the researchers. At present, MOFs have been widely used

Received: July 17, 2020

Accepted: October 8, 2020 
in gas storage, ${ }^{21-23}$ toxic gas removal, ${ }^{24}$ separation, $^{25,26}$ photocatalysis, ${ }^{27}$ chemical sensors, ${ }^{28}$ and so on. In recent years, some water-stable MOFs have been used for the remove pollutants from wastewater, including removal of organic dyes, ${ }^{29,30}$ heavy metal ions, ${ }^{31,32}$ and pharmaceuticals and personal care products ${ }^{3,34}$ from water. The possible mechanisms for adsorptive removal of pollutants over MOFs mainly include electrostatic adsorption, acid-base reaction, $\pi-\pi$ complexation, and hydrogen bond. ${ }^{35}$ Previous studies have shown that berberine is mainly removed through hydrogen-bonding formation with berberine acting as a $\mathrm{H}$ acceptor, ${ }^{15}$ while it is reported that MOFs could be good $\mathrm{H}$ donors. $^{36}$ Thus, MOFs might be promising materials for berberine adsorption. However, the use of MOFs for berberine removal has not been reported.

The overall objective of the current study is to explore the possibility of removing berberine from water by MOFs. MIL$101(\mathrm{Fe})$ was synthesized and used for berberine removal in this study. The effect of temperature, adsorbent dosage, solution $\mathrm{pH}$, and chloride on the material's properties for berberine adsorption was examined. The capacity and the kinetics of the material for berberine removal were studied by conducting batch experiments. Also, the associated mechanism for berberine removal by the material was proposed together with experimental results and theoretical calculations.

\section{RESULTS AND DISCUSSION}

2.1. Effect of Temperature and Adsorbent Dosage on the Adsorption of Berberine by MIL-101(Fe). The influence of temperature on berberine removal was studied under the temperature of 298,308 , and $318 \mathrm{~K}$, as shown in Figure 1a. The results showed that the removal of berberine increased with the increase of temperature. When the temperature increased from 298 to $308 \mathrm{~K}$, the adsorption amount of berberine increased from 61.55 to $82.03 \mathrm{mg} / \mathrm{g}$. Further increasing the temperature to $318 \mathrm{~K}$ could increase the adsorption amount of berberine to $103.38 \mathrm{mg} / \mathrm{g}$. However, considering the energy consumption of temperature increase, this study mainly focused on the removal of berberine at room temperature.

Furthermore, the thermodynamic parameters including the standard Gibbs free energy change $\left(\Delta G^{\circ}\right)$, enthalpy change $\left(\Delta H^{\circ}\right)$, and entropy change $\left(\Delta S^{\circ}\right)$ were calculated for the adsorption of berberine on MIL-101(Fe) according to the method reported in the previous study. ${ }^{29}$ As shown in Table 1 , the Gibbs free energy changes were positive at 298 and $308 \mathrm{~K}$, indicating that the adsorption process is not spontaneous for the adsorption of berberine on MIL-101(Fe). While the Gibbs free energy change was negative at $318 \mathrm{~K}$, which indicates that the adsorption process is spontaneous under $318 \mathrm{~K}$. Also, $\Delta H^{\circ}$ and $\Delta S^{\circ}$ were positive for the adsorption of berberine on MIL$101(\mathrm{Fe})$, indicating that the adsorption process was endothermic.

The effect of the dosage of MIL-101(Fe) on the adsorption of berberine was also studied, as shown in Figure $1 \mathrm{~b}$. It can be seen that the adsorption amount of berberine for per unit of adsorbent decreased with the increase of adsorbent dosage. However, the concentration of removed berberine increased with the increase of adsorbent dosage, as seen in Figure S1. When the dosage of MIL-101 $(\mathrm{Fe})$ increased from 0.2 to $1 \mathrm{~g} / \mathrm{L}$, the removed berberine concentration increased from 21.68 to $61.55 \mathrm{mg} / \mathrm{L}$. However, when the dosage of MIL-101(Fe) was higher than $1.0 \mathrm{~g} / \mathrm{L}$, further increase in the adsorbent dosage
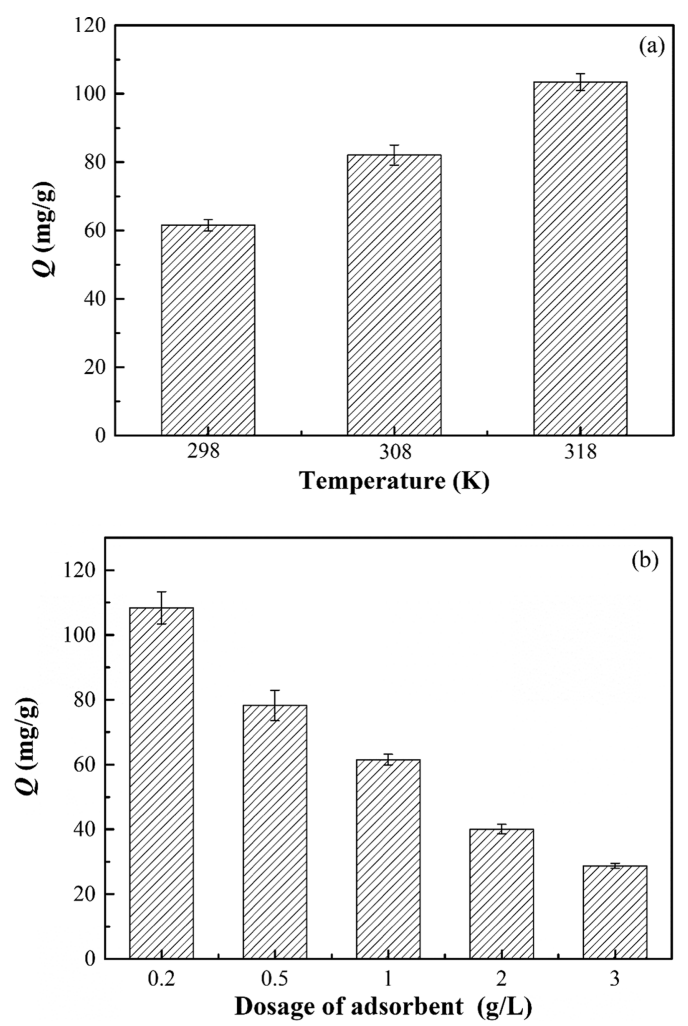

Figure 1. Effect of temperature (a) and adsorbent dosage (b) on the adsorption of berberine by MIL-101 $(\mathrm{Fe})$. Experimental conditions: (a) the dosage of MIL-101 $(\mathrm{Fe})=1.0 \mathrm{~g} / \mathrm{L}$; initial concentration of berberine $=200 \mathrm{mg} / \mathrm{L}$; initial $\mathrm{pH}=7.0$; and equilibration time of 12 $\mathrm{h}$; and (b) initial concentration of berberine $=200 \mathrm{mg} / \mathrm{L}$; initial $\mathrm{pH}=$ 7.0; equilibration time of $12 \mathrm{~h}$; and temperature of $298 \mathrm{~K}$.

Table 1. Thermodynamic Parameters for the Adsorption of Berberine on MIL-101(Fe)

$\begin{array}{ccccc}\text { temperature } & \Delta G(\mathrm{~kJ} / \mathrm{mol}) & \Delta H(\mathrm{~kJ} / \mathrm{mol}) & \Delta S(\mathrm{~kJ} /(\mathrm{mol} \mathrm{K})) & R^{2} \\ 298 & 2.04 & 34.37 & 0.11 & 0.9999 \\ 308 & 0.97 & & & \\ 318 & -0.13 & & & \\ & & & & \end{array}$

resulted in less increase in berberine adsorption. Especially, when the MIL-101 $(\mathrm{Fe})$ dosage increased from 2 to $3 \mathrm{~g} / \mathrm{L}$, the removal of berberine increased from 80.07 to $86.27 \mathrm{mg} / \mathrm{L}$. Thus, considering the adsorption capacity of the material and the removal efficiency of berberine, the dosage of $1.0 \mathrm{~g} / \mathrm{L}$ would be used in the following study.

2.2. Effect of $\mathrm{pH}$ on the Adsorption of Berberine by MIL-101(Fe). The $\mathrm{pH}$ of the solution is usually very important for the adsorption of organics. In this study, the influence of the initial $\mathrm{pH}$ on berberine removal by MIL-101(Fe) was conducted at $\mathrm{pH}$ from 4 to 10 , as shown in Figure 2. As illustrated, the initial $\mathrm{pH}$ did not have much influence on the removal of berberine by MIL-101(Fe). The adsorption amount of berberine was almost the same at the initial $\mathrm{pH}$ from 4 to 10 . This result is different from that of other studies. Shan et al. ${ }^{3}$ found that the initial $\mathrm{pH}$ had a great influence on the removal of berberine by resin $\mathrm{H} 103$. This is because the adsorption of berberine onto resin is highly dependent on the size of berberine in the solution. Berberine molecules dissociate into $\mathrm{R}^{+}$and $\mathrm{Cl}^{-}$when the $\mathrm{pH}$ is lower than 7.0 but form $\mathrm{R}-\mathrm{OH}^{2+}$ ions when the $\mathrm{pH}$ is higher than 7.0. Also, at a $\mathrm{pH}$ of 7.0, 


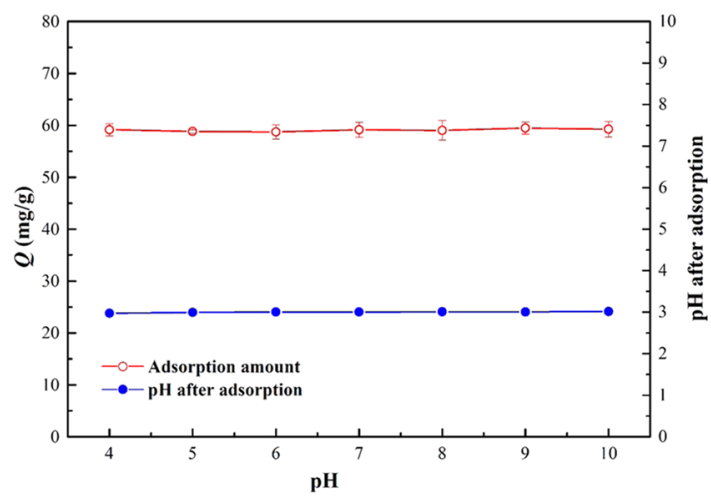

Figure 2. Effect of $\mathrm{pH}$ on the removal of berberine by MIL-101(Fe) (the dosage of MIL-101(Fe) $=1.0 \mathrm{~g} / \mathrm{L}$; initial concentration of berberine $=200 \mathrm{mg} / \mathrm{L}$; equilibration time of $12 \mathrm{~h}$; and temperature of $298 \mathrm{~K})$.

berberine exists as neutral molecules. ${ }^{3}$ Therefore, the initial $\mathrm{pH}$ would affect the size of berberine in the solution, resulting in the initial $\mathrm{pH}$ having a great influence on the adsorption of berberine by resin $\mathrm{H} 103$. In this study, the $\mathrm{pH}$ of the solution with different initial $\mathrm{pH}$ was all about 3 after the adsorption of berberine by MIL-101(Fe), as shown in Figure 2. The $\mathrm{pH}$ of the solution decreased rapidly after the addition of MIL$101(\mathrm{Fe})$ due to the strong acidity of the material. Therefore, the initial $\mathrm{pH}$ did not have much influence on the removal of berberine by MIL-101(Fe).

In particular, berberine wastewater is usually highly acidic with $\mathrm{pH}$ in the range from 0.06 to $1.2 .{ }^{9,37}$ However, the adsorbents used to remove berberine in the current studies are usually less effective in removing berberine under acidic conditions. For example, the adsorption capacity of polymeric resin $\mathrm{H} 103$ for berberine decreased obviously when the $\mathrm{pH}$ was less than $5 .^{3}$ Similarly, the adsorption capacity of berberine on ZSM-5 molecular sieves reached the maximum at $\mathrm{pH} 8$ and decreased with the decrease in $\mathrm{pH}^{38}$ However, MIL-101(Fe) synthesized in this study is suitable for the removal of berberine under acidic conditions, which is favorable for its practical application.

2.3. Effect of Chloride on the Removal of Berberine by MIL-101(Fe). Because berberine wastewater usually contains high concentrations of chloride $\left(\mathrm{Cl}^{-}\right)$in the range from 6555 to $12670 \mathrm{mg} / \mathrm{L},{ }^{39,40}$ it is necessary to investigate the influence of chloride on the adsorption of berberine by MIL$101(\mathrm{Fe})$. The removal of berberine by MIL-101(Fe) in the presence of chloride was examined at different concentrations, as shown in Figure 3. It can be seen that $\mathrm{Cl}^{-}$had little effect on the adsorption of berberine at low concentrations. However, it was found that chloride could promote berberine removal by MIL-101(Fe) when the concentration of chloride was more than $50 \mathrm{mM}(2922 \mathrm{mg} / \mathrm{L})$. This result indicated that the presence of chloride was advantageous for the adsorption of berberine from berberine wastewater by MIL-101(Fe). This might be because berberine molecules dissociate into $\mathrm{R}^{+}$and $\mathrm{Cl}^{-}$under reaction conditions. The presence of high concentrations of $\mathrm{Cl}^{-}$may lead to the formation of neutral berberine molecules, which is favorable for the adsorption of berberine. ${ }^{3}$ Thus, the high concentration of chloride in berberine wastewater could promote the adsorption of berberine by MIL-101(Fe), which is beneficial for the application of MIL-101(Fe) in berberine wastewater treatment.

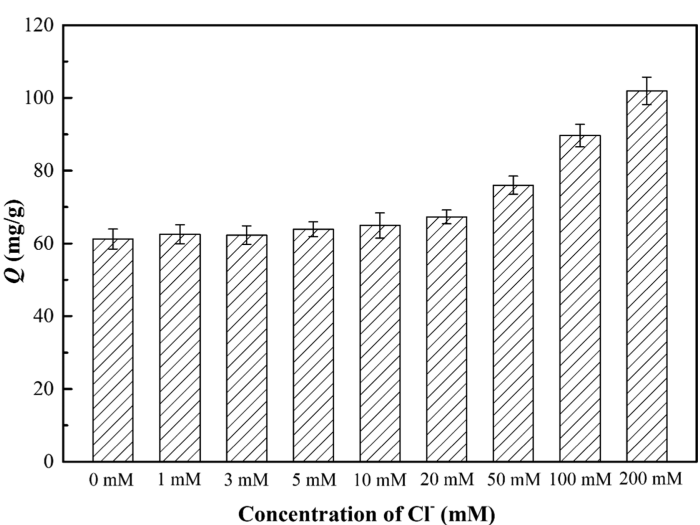

Figure 3. Effect of chloride on berberine removal by MIL-101(Fe) (the dosage of MIL-101 $(\mathrm{Fe})=1.0 \mathrm{~g} / \mathrm{L}$; initial concentration of berberine $=200 \mathrm{mg} / \mathrm{L}$; initial $\mathrm{pH}=7.0$; and temperature of $298 \mathrm{~K}$ ).

2.4. Isothermal Adsorption of Berberine by MIL101(Fe). Adsorption isotherm of berberine by MIL-101(Fe) at $\mathrm{pH} 7$ is shown in Figure 4. It can be seen that the adsorption of berberine increased with the increase of berberine concentration. To further analyze the adsorption behavior of berberine on MIL-101(Fe), Langmuir isotherm model, Freundlich isotherm model, and Temkin isotherm model were used to analyze the batch adsorption results. The fitting parameters of Langmuir, Freundlich, and Temkin isotherm are listed in Table 2. The fitting results showed that the Langmuir equation was better to analyze the isotherm data than the Freundlich equation or the Temkin equation. The correlation coefficients from the Langmuir equation were higher than 0.99 . Based on the fitting of the Langmuir equation, the synthesized material had a maximum capacity of $163.93 \mathrm{mg} / \mathrm{g}$ for berberine, which is higher than those of the previously reported adsorbents (Table 3 ). These results demonstrate that MIL-101(Fe) has good prospects for the removal of berberine from water.

2.5. Kinetics of Berberine Removal by MIL-101(Fe). Kinetics of berberine adsorption by MIL-101(Fe) was

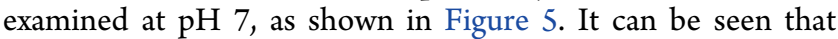
the berberine was adsorbed by MIL-101(Fe) quickly in the first $30 \mathrm{~min}$, and the concentration of berberine decreased fast. The adsorption of berberine by MIL-101(Fe) reached an equilibrium in about $6 \mathrm{~h}$. At the beginning of the reaction, MIL-101(Fe) contained a lot of adsorption sites on the surface of the material and the berberine in the solution can be adsorbed quickly. However, the reaction sites on the surface of the material were consumed gradually with the increase in the reaction time, and the decrease in the concentration of berberine in the solution resulted in a slower reaction rate. Further, the typical kinetic models including intraparticle diffusion, pseudo-first-order and pseudo-second-order models were used to fit the experimental results and analyze the adsorption kinetics of berberine on MIL-101(Fe). The kinetic parameters and coefficients of the three models are shown in Table 4. It can be seen that the correlation coefficient of the pseudo-second-order model is greater than 0.99, which is much higher than that of the two other models. Thus, the experimental data can be fitted well to the pseudo-secondorder kinetic model rather than to the intraparticle diffusion equation or the pseudo-first-order equation. This indicated that the rate-limiting step for the adsorption of berberine on MIL-101(Fe) may be a chemisorption process. 

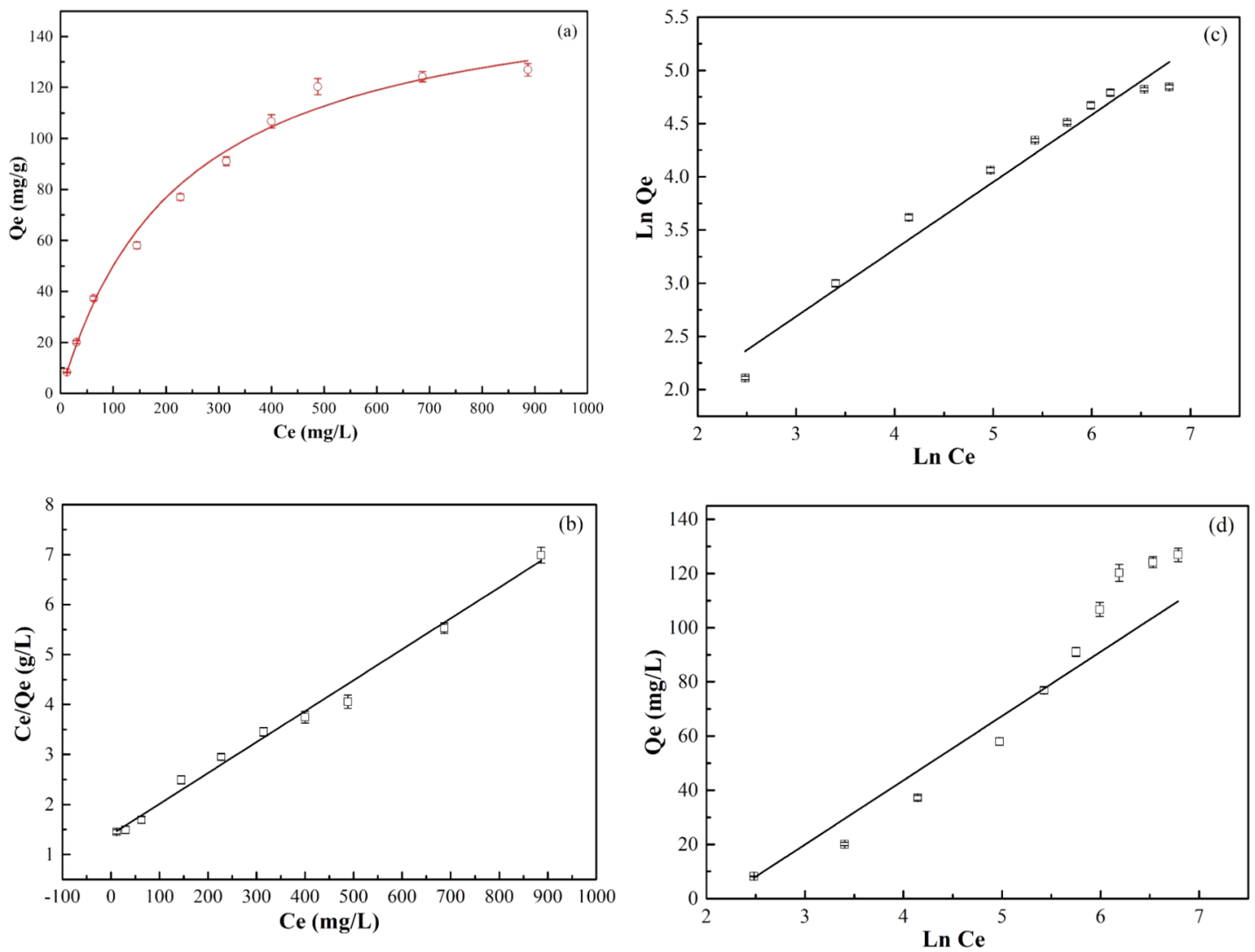

Figure 4. Adsorption isotherms of berberine by MIL-101(Fe) (a) and fitting of Langmuir (b), Freundlich (c), and Temkin (d) models. (the dosage of $\mathrm{MIL}-101(\mathrm{Fe})=1.0 \mathrm{~g} / \mathrm{L}$; initial $\mathrm{pH}=7.0$; equilibration time of $12 \mathrm{~h}$; and temperature of $298 \mathrm{~K})$.

Table 2. Langmuir, Freundlich, and Temkin Parameters for the Adsorption of Berberine on MIL-101(Fe)

\begin{tabular}{|c|c|c|c|c|c|c|c|c|}
\hline \multicolumn{3}{|c|}{ Langmuir $Q_{\mathrm{e}}=\frac{K_{\mathrm{L}} Q_{\max } C_{\mathrm{e}}}{1+K_{\mathrm{L}} C_{\mathrm{e}}}$} & \multicolumn{3}{|c|}{ Freundlich $Q_{e}=K_{\mathrm{F}} C_{\mathrm{e}}{ }^{1 / n}$} & \multicolumn{3}{|c|}{ Temkin $Q_{\mathrm{e}}=B \ln K_{\mathrm{T}}+B \ln C_{\mathrm{e}}$} \\
\hline$Q_{\max }(\mathrm{mg} / \mathrm{g})$ & $K_{\mathrm{L}}$ & $R^{2}$ & $n$ & $K_{\mathrm{F}}$ & $R^{2}$ & B & $K_{\mathrm{T}}$ & $R^{2}$ \\
\hline 163.93 & 0.0044 & 0.9914 & 1.574 & 2.2105 & 0.9698 & 30.597 & 0.0705 & 0.9603 \\
\hline
\end{tabular}

Table 3. Comparison of Maximum Berberine Adsorption Capacities of Various Adsorbents

\begin{tabular}{lccc}
\multicolumn{1}{c}{ adsorbents } & conditions & $\begin{array}{c}\mathrm{Q}_{\max } \\
(\mathrm{mg} / \mathrm{g})\end{array}$ & reference \\
$\begin{array}{lccc}\text { molecularly imprinted polymer AD- } \\
\quad 303 \mathrm{~K}, 12 \mathrm{~h}\end{array}$ & 7.95 & 58 \\
$\begin{array}{l}\text { berberine hydrochloride imprinted } \\
\text { polymers }\end{array}$ & $298 \mathrm{~K}, 5 \mathrm{~h}$ & 10.11 & 12 \\
$\begin{array}{l}\text { macroporous resin AB-8 } \\
\text { macroporous resin HPD722 }\end{array}$ & $303 \mathrm{~K}, 28 \mathrm{~h}$ & 65.5 & 59 \\
macroporous resin HPD100B & $303 \mathrm{~K}, 28 \mathrm{~h}$ & 89.8 & 59 \\
macroporous resin HPD300 & $303 \mathrm{~K}, 28 \mathrm{~h}$ & 97.1 & 59 \\
mIL-101(Fe) & $303 \mathrm{~K}, 28 \mathrm{~h}$ & 117.8 & 59 \\
& $298 \mathrm{~K}, 12 \mathrm{~h}$ & 163.93 & this \\
& & & work
\end{tabular}

2.6. Characterization of MIL-101(Fe) before and after Adsorption. To observe the changes in the material before and after the adsorption of berberine, scanning electron microscopy (SEM), X-ray power diffraction (XRD), Fourier transform infrared spectroscopy (FTIR), and X-ray photoelectron spectroscopy (XPS) analysis were conducted. The morphologies of the MIL-101(Fe) before and after the adsorption of berberine were observed by SEM, as shown in Figure 6. The synthesized MIL-101(Fe) had typical octahedral shapes before the adsorption of berberine, which is in accordance with the previous reports. ${ }^{41}$ The morphology of the material changed obviously after the adsorption of berberine, as presented in Figure 6b. After the reaction with berberine, the octahedron shape of MIL-101(Fe) was depressed. This result indicated that the metal site of MIL$101(\mathrm{Fe})$ may not participate in the reaction with berberine.

The XRD spectra of the material before and after the adsorption of berberine are shown in Figure 7. The XRD spectra of the synthesized MIL-101(Fe) were well in agreement with the previously reported data, ${ }^{42}$ which indicated that MIL-101 $(\mathrm{Fe})$ was successfully synthesized in this study. After the adsorption of berberine, the XRD spectra of the material changed. However, the typical main diffraction peaks did not change. Shown in Figure 8 are the FTIR spectra of MIL-101 $(\mathrm{Fe})$ before and after the adsorption of berberine at $\mathrm{pH} 7$ for $12 \mathrm{~h}$. The FTIR spectra of the synthesized material confirmed the successful synthesis of MIL-101(Fe). ${ }^{43}$ The bands in the region of $1600-1400 \mathrm{~cm}^{-1}$ represent the asymmetrical and symmetrical stretchings of $\mathrm{O}-\mathrm{C}-\mathrm{O}$, which are the typical characteristic peaks of MIL- $101{ }^{44}$ The peaks at 590 and $790 \mathrm{~cm}^{-1}$ can be attributed to the vibration of $\mathrm{Fe}-$ $\mathrm{O}^{44,45}$ and $\mathrm{C}-\mathrm{H}$ bending vibrations of the benzene, ${ }^{46}$ respectively. After the adsorption of berberine, the main peaks of the FTIR spectra for the material weakened, while the 

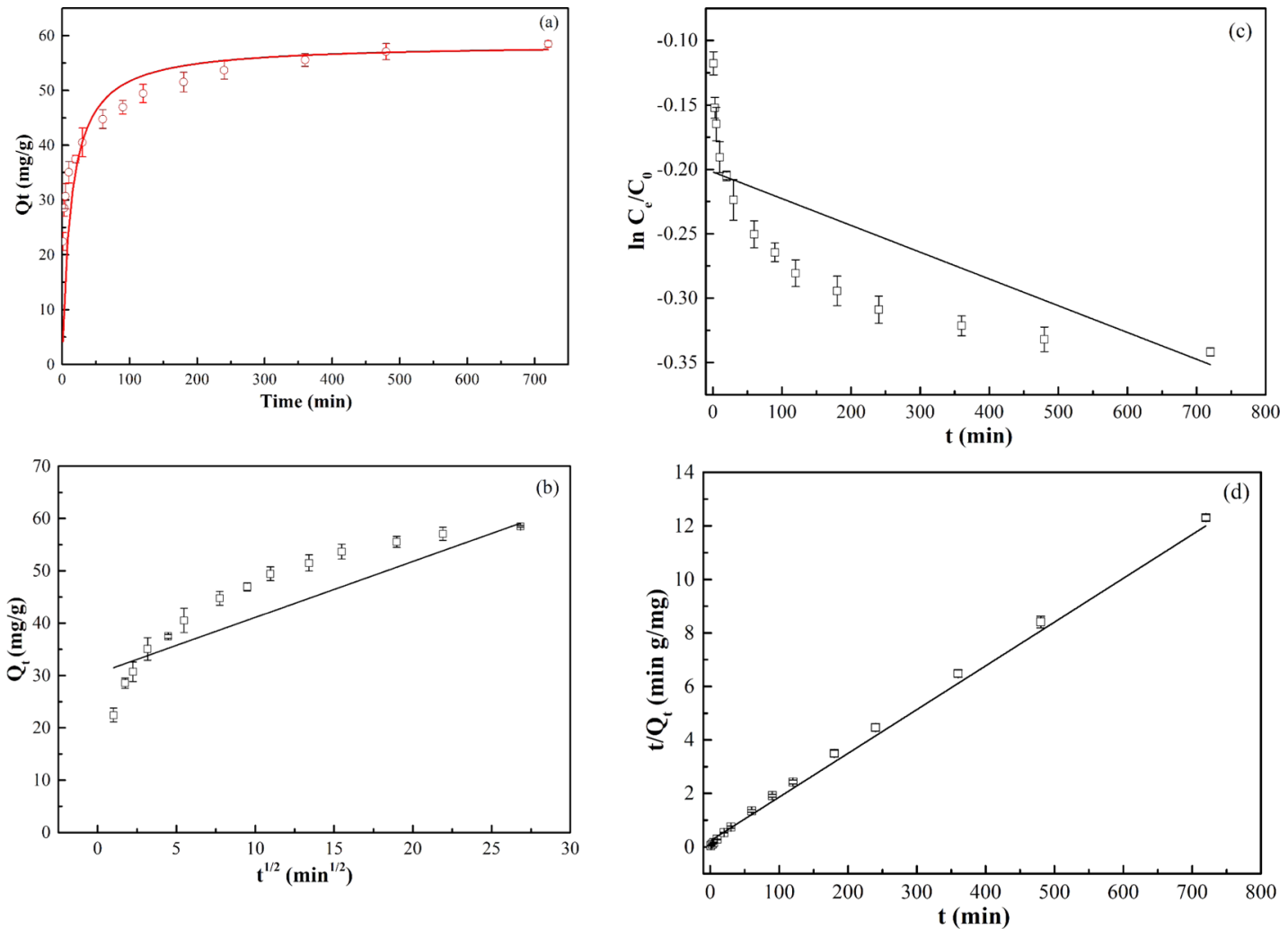

Figure 5. Adsorption kinetics of berberine by MIL-101(Fe) (a) and fitting of the intraparticle diffusion model (b), pseudo-first-order model (c), and pseudo-second-order model (d) (the dosage of MIL-101(Fe) = $1.0 \mathrm{~g} / \mathrm{L}$; initial concentration of berberine $=200 \mathrm{mg} / \mathrm{L}$; initial pH = 7.0; temperature of $298 \mathrm{~K}$ ).

Table 4. Kinetic Parameters and Coefficients of the Intraparticle Diffusion, Pseudo-First-Order, and Pseudo-Second-Order Model for the Adsorption of Berberine on MIL-101(Fe)

\begin{tabular}{|c|c|c|c|c|c|c|}
\hline \multicolumn{2}{|c|}{$\begin{array}{c}\text { intraparticle diffusion model } \\
Q_{t}=K_{p} t^{1 / 2}+C\end{array}$} & \multicolumn{2}{|c|}{ pseudo-first-order model $C_{\mathrm{t}}=C_{0} \mathrm{e}^{-\mathrm{K}_{1} \mathrm{t}}$} & \multicolumn{3}{|c|}{ pseudo-second-order model $\frac{t}{Q_{t}}=\frac{1}{K_{2} Q^{2}}+\frac{t}{Q_{e}}$} \\
\hline$K_{\mathrm{p}}$ & $R^{2}$ & $K_{1}\left(\min ^{-1}\right)$ & $R^{2}$ & $\mathrm{Q}_{\mathrm{e}}(\mathrm{mg} / \mathrm{g})$ & $K_{2}(\mathrm{~g} /(\mathrm{mg} \min )$ & $R^{2}$ \\
\hline 1.3049 & 0.8529 & 0.0003 & 0.6520 & 58.48 & 0.0013 & 0.9985 \\
\hline
\end{tabular}
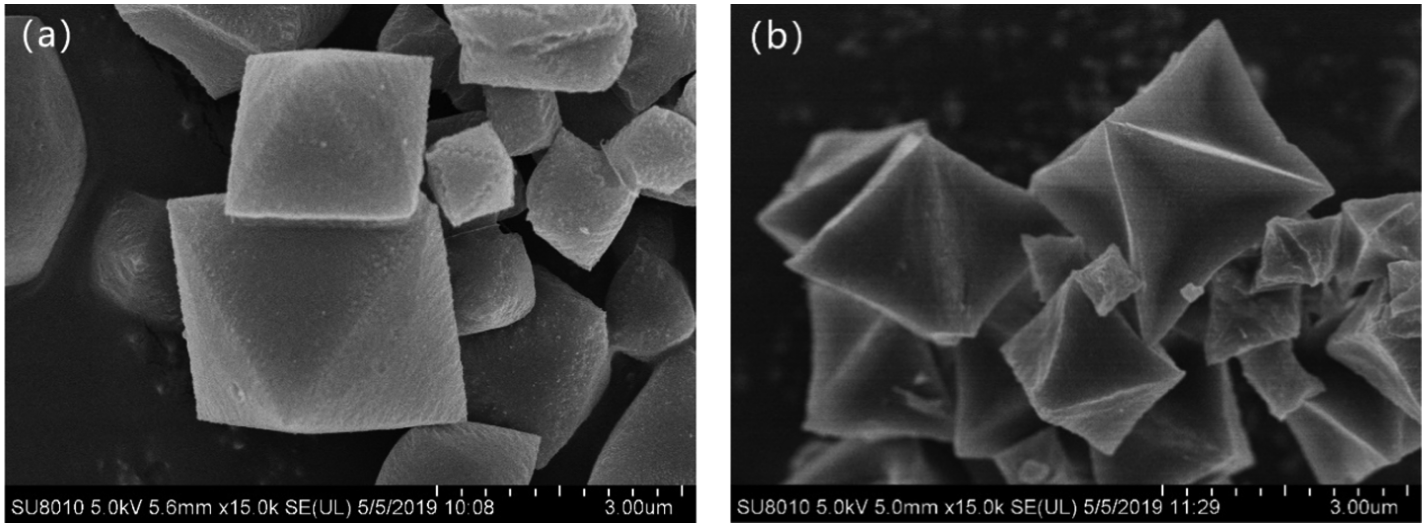

Figure 6. SEM images of MIL-101(Fe) before (a) and after (b) adsorption of berberine.

position of the main peaks did not change, indicating no changes in the chemical bond.

Furthermore, to analyze the surface chemistry of MIL101(Fe) before and after the adsorption of berberine, XPS was conducted, as shown in Figure 9. Figure 9a shows the fullsurvey spectrum of MIL-101(Fe), in which the signals of $\mathrm{Fe}, \mathrm{C}$, and $\mathrm{O}$ could be detected. Before the adsorption, the XPS spectra of $\mathrm{Fe} 2 \mathrm{p}$ showed two peaks at 711.80 and 725.60, which can be assigned to $\mathrm{Fe}^{3+}$. Because that the Fe species in MIL-101 was $\mathrm{Fe}^{3+}$, 447 the presence of $\mathrm{Fe}^{3+}$ validated the formation of MIL-101(Fe) with Fe as the metal site. After the adsorption, the XPS spectra of Fe 2p consist of two subpeaks at 711.47 and 725.31, which were also attributed from $\mathrm{Fe}^{3+}$. This result indicated that $\mathrm{Fe}$, as the metal site of the material, did 


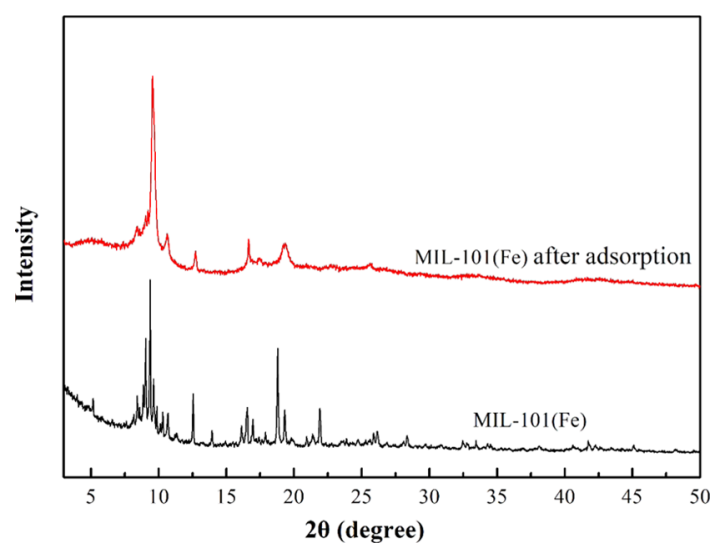

Figure 7. XRD of MIL-101(Fe) before and after the adsorption of berberine.

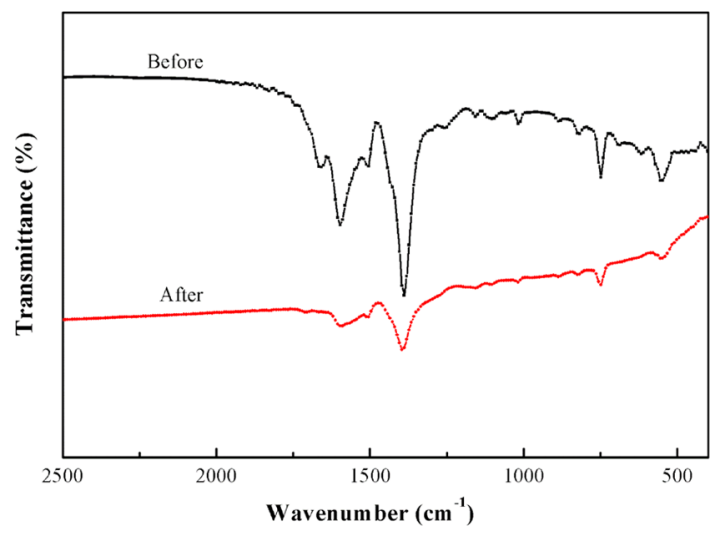

Figure 8. FTIR spectra of MIL-101(Fe) before and after the adsorption of berberine.

not participate in the reaction with berberine. Combined with the results of XRD and FTIR, the chemical composition of the material may not change after the adsorption of berberine.

2.7. Adsorption Mechanism. It is important to understand the plausible mechanism of the interactions between the adsorbent and adsorbate. Several adsorption mechanisms such as electrostatic interaction, acid/base complexing, $\pi-\pi$ interactions, and hydrogen bonding have been used to explain the adsorption of organics over MOFs. ${ }^{35}$ From the characterization results of MIL-101(Fe) before and after adsorption, it can be concluded that no obvious chemical reaction occurred between MIL-101(Fe) and berberine. To further understand the mechanism of the adsorption of berberine by MIL$101(\mathrm{Fe})$, theoretical calculations were performed to analyze the weak interactions between MIL-101(Fe) and berberine. Figure 10 shows the possible adsorption site of MIL-101(Fe) for berberine (Figure $10 \mathrm{a}-\mathrm{c}$ ) and the isosurface of $\delta \mathrm{g}$ (Figure $10 \mathrm{~d})$. The green area in the isosurface of $\delta \mathrm{g}$ between MIL$101(\mathrm{Fe})$ and berberine represents $\pi-\pi$ interactions, and the blue area represents hydrogen bonding. It can be seen that there is a weak hydrogen bond between MIL-101(Fe) and berberine, while $\pi-\pi$ interactions play the main role in the adsorption of berberine by MIL-101(Fe). Thus, it can be inferred that berberine is mainly adsorbed on MIL-101(Fe) through $\pi-\pi$ interactions.
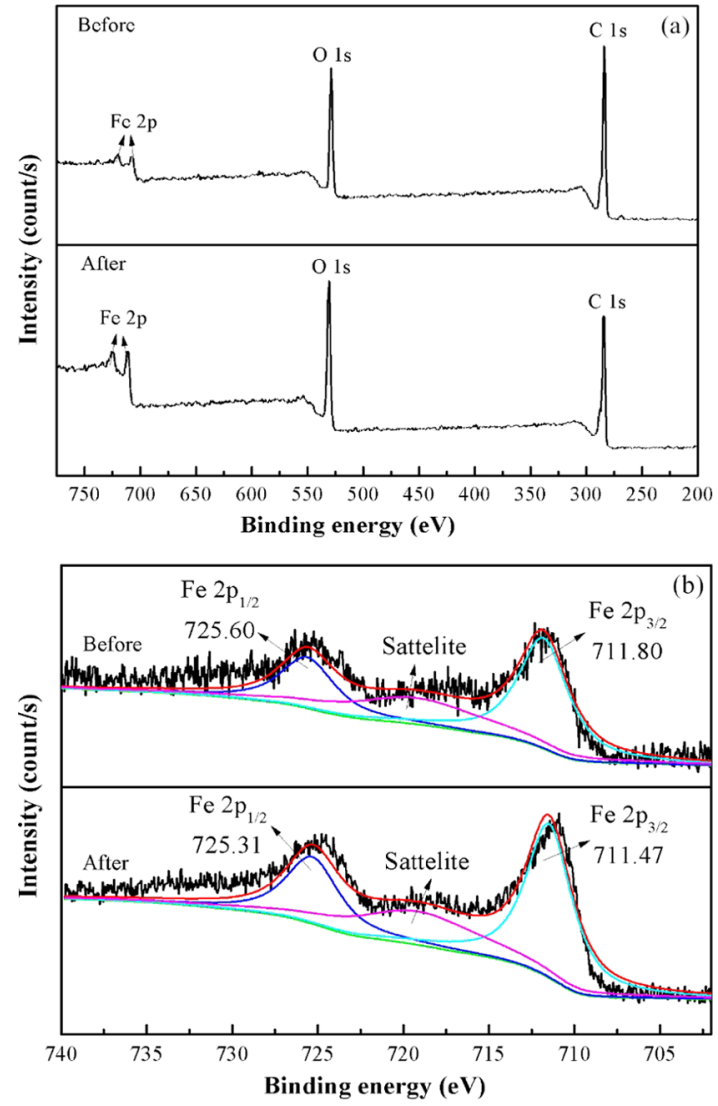

Figure 9. XPS spectra of MIL-101(Fe) before and after the adsorption of berberine: full-survey (a) and $\mathrm{Fe} 2 \mathrm{p}(\mathrm{b})$.

\section{CONCLUSIONS}

MIL-101(Fe) was used for berberine removal from water in this study. As a new type of porous materials, MIL-101(Fe) showed some advantages in the removal of berberine. First, MIL-101 $(\mathrm{Fe})$ can be used for berberine removal under acidic conditions. Second, a high concentration of chloride could promote the removal of berberine by MIL-101(Fe). Third, MIL-101(Fe) has a high capacity for berberine with the maximum sorption capacity of $163.93 \mathrm{mg} / \mathrm{g}$ at $\mathrm{pH} 7$. For the removal mechanism of berberine by MIL-101(Fe), the characterization results indicate that no chemical reaction occurred between berberine and MIL-101(Fe). Through theoretical calculation, it can be inferred that the main mechanism for the adsorption of berberine by MIL-101(Fe) can be attributed to $\pi-\pi$ interactions. The findings of this study suggest that MIL-101(Fe) is a promising sorbent for berberine removal from water. For future research, the capacity of MIL-101(Fe) for berberine can be further improved through the modification of nitrogen-containing functional groups to enhance the hydrogen-bonding reaction between adsorbent and berberine.

\section{MATERIALS AND METHODS}

4.1. Materials. The following reagents were used in this study: ferric chloride hexahydrate and terephthalic acid (TPA) were purchased from Shanghai Macklin Biochemical Co., Ltd. $\mathrm{NaCl}, \mathrm{NaNO}_{3}, \mathrm{Na}_{2} \mathrm{SO}_{4}, \mathrm{NaHCO}_{3}, \mathrm{NaOH}, \mathrm{HCl}, \mathrm{N}, \mathrm{N}-$ dimethylformamide (DMF), and ethanol were provided by Sinopharm Group, China. 

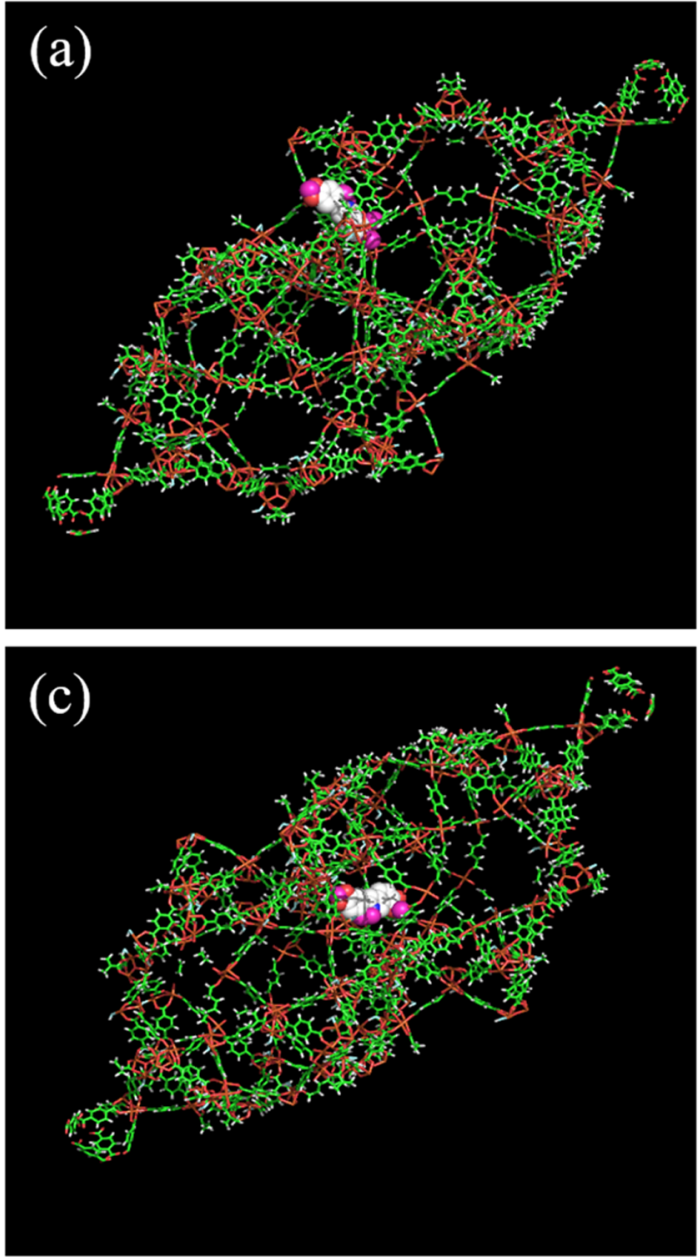

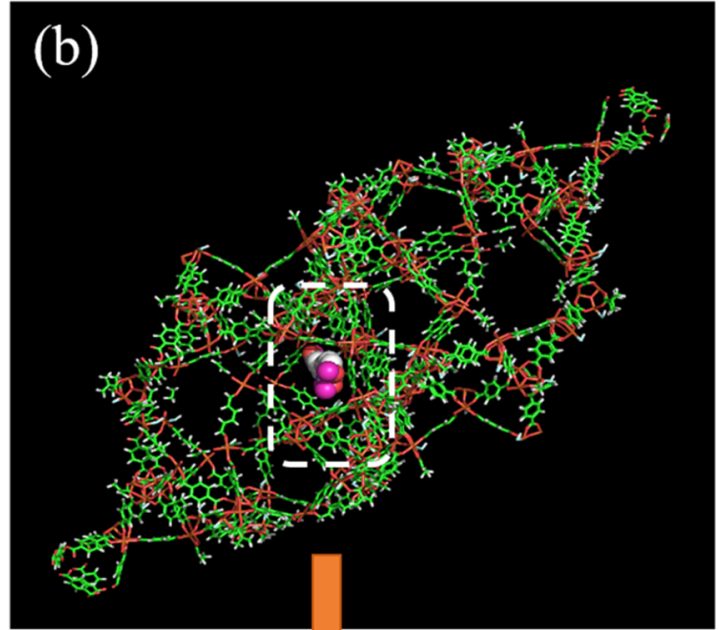

(d)

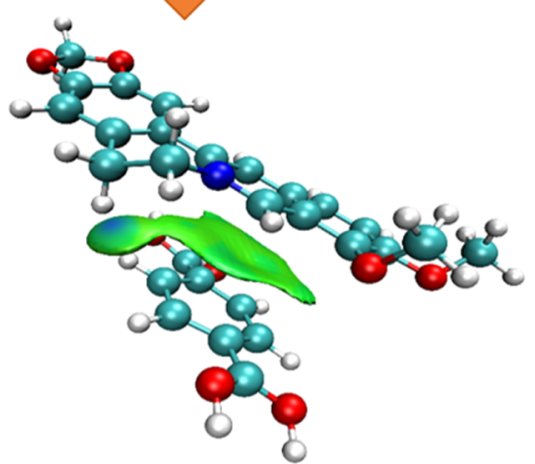

Figure 10. Weak interactions between MIL-101(Fe) and berberine: the possible adsorption site of MIL-101(Fe) for berberine (a-c) and the isosurface of $\delta \mathrm{g}(\mathrm{d})$.

4.2. Preparation of MIL-101(Fe). MIL-101(Fe) was synthesized through a hydrothermal synthesis method reported previously, with slight modifications. ${ }^{43}$ First, ferric chloride hexahydrate and terephthalic acid were dissolved in DMF solution in a ratio of $2: 1$. Then, the mixture was transferred to a Teflon-lined autoclave and put into a preheated (at $110^{\circ} \mathrm{C}$ ) electric oven and maintained for $20 \mathrm{~h}$. The autoclave was cooled to room temperature after the reaction and a solid product was recovered by centrifugation. The product was washed with DMF and ethanol 2 times, respectively. And then, the product was vacuum-dried at $60^{\circ} \mathrm{C}$ for $24 \mathrm{~h}$. The prepared MIL-101(Fe) had a Brunauer-Emmett-Teller (BET) surface area of $1312 \mathrm{~m}^{2} / \mathrm{g}$.

4.3. Characterization of Materials. The synthesized MIL-101(Fe) was characterized by Brunauer-Emmett-Teller (BET) surface area, scanning electron microscopy (SEM), Xray power diffraction (XRD), Fourier transform infrared spectroscopy (FTIR), and X-ray photoelectron spectroscopy (XPS). For the characterization of MIL-101(Fe) after adsorption of berberine, the material after the reaction was washed with water and ethanol two times, respectively. And then, the product was vacuum-dried at $60{ }^{\circ} \mathrm{C}$ for $24 \mathrm{~h}$ and used for characterization.

The specific surface area of MIL-101(Fe) was calculated by the BET equation from $\mathrm{N}_{2}$ adsorption/desorption isotherms, which was conducted by Quadrasorb SI-MP. The morphology of the material before and after the adsorption of berberine was observed by SEM (Hitachi SU8010, Japan). The synthesized samples were also characterized by FTIR (Excalibur 3100, Varian) in the range of $400-4000 \mathrm{~cm}^{-1}$ to identify the functional groups on the adsorbent surface. X-ray diffraction analysis of the samples before and after reaction with berberine was conducted using X-ray power diffraction in the range from 3 to $50^{\circ}$. In addition, to determine the surface chemical composition of the material before and after the adsorption of berberine, XPS (ESCALAB-MKII, VG Co., Bruker, Germany) analysis was performed.

4.4. Batch Experiments. 4.4.1. Effect of Temperature on Berberine Removal. The effect of temperature on the removal of berberine by MIL-101(Fe) was conducted. In a typical test, $20 \mathrm{mg}$ of MIL-101(Fe) was mixed with $20 \mathrm{~mL}$ of $200 \mathrm{mg} / \mathrm{L}$ berberine solution at an initial $\mathrm{pH}$ of 7.0. Then, the mixture reacted in a shaking table for $12 \mathrm{~h}$ at temperatures of 298, 308, and $318 \mathrm{~K}$, respectively. After reaching equilibrium, the mixture was filtered through a $0.22 \mu \mathrm{m}$ syringe filter, and the concentration of berberine in the filtrate was determined using an ultraviolet-visible (UV-vis) spectrophotometer at $345 \mathrm{~nm}$. The experiment was repeated three times.

4.4.2. Effect of Adsorbent Dosage on Berberine Removal. The effect of adsorbent dosage on the removal of berberine by MIL-101(Fe) was also conducted at a temperature of $298 \mathrm{~K}$. The test procedures were similar to the above experiment, 
except that a different adsorbent dosage was used. The experiment was also repeated three times.

4.4.3. Effect of $\mathrm{pH}$ on Berberine Removal. Batch experiments were carried out at $298 \mathrm{~K}$ to investigate the berberine adsorption as a function of the initial $\mathrm{pH}$. The $\mathrm{pH}$ of the solution was adjusted by $\mathrm{HCl}$ or $\mathrm{NaOH}$. All other experimental conditions and procedures were similar to the above experiments. The experiment was also repeated three times.

4.4.4. Effect of Chloride on Berberine Removal. The influence of chloride on berberine removal by MIL-101(Fe) was also studied at initial $\mathrm{pH}$ 7. Different levels of concentration of $\mathrm{Cl}^{-}(1,3,5,10,20,50,100$, and $200 \mathrm{mM})$ were tested. All other experimental conditions and procedures were similar to the above experiments. The experiment was also repeated three times.

4.4.5. Adsorption Isotherms. The capacity of MIL-101(Fe) for berberine removal was examined at an initial $\mathrm{pH}$ of 7 by conducting the batch equilibrium experiment. The test procedures were similar to the above experiment, except that varied berberine concentrations were used. The experiment was repeated three times. Equilibrium sorption data were plotted using the Langmuir, Freundlich, and Temkin models, and the adsorption capacity $\left(Q_{\max }, \mathrm{mg} / \mathrm{g}\right)$ of the sorbent was obtained from the fitting parameters.

4.4.6. Kinetics Study. The sorption kinetics of berberine by MIL-101 $(\mathrm{Fe})$ was examined at $\mathrm{pH} 7$ in a conical flask that contained $200 \mathrm{~mL}$ of $200 \mathrm{mg} / \mathrm{L}$ berberine solution at the start of the test. All other experimental conditions were identical to the above experiments. The test mixture was sampled at the desired time interval with a $5 \mathrm{~mL}$ syringe and filtered immediately through a $0.22 \mu \mathrm{m}$ membrane filter for an analysis of residual berberine. The experiment was also repeated three times.

4.5. Theoretical Calculations. Theoretical calculations were conducted to analyze the weak interactions between adsorbent and berberine. Multiwfn 3.7 software $^{48}$ was used to calculate the isosurface of the $\delta \mathrm{g}$ function of the independent gradient model (IGM) ${ }^{49}$ after geometry optimization. The optimization of the molecular geometry with a default solvent model under the level of PBE1PBE/6-311G $*^{50-54}$ was carried out by Gaussian software. ${ }^{55}$ The images of molecular structure and isosurface of the $\delta \mathrm{g}$ function were obtained by VMD software. ${ }^{56}$ In addition, the molecular docking was realized by AutoDockTools and Vina. Because the structure file of MIL101(Fe) was not found in the Cambridge Crystallographic Data Center (CCDC), while the structure of MIL-101 $(\mathrm{Fe})$ is the same as that of MIL-101(Cr), ${ }^{57}$ the crystal file of MIL$101(\mathrm{Fe})$ was obtained by replacing $\mathrm{Cr}$ of MIL-101(Cr) coming from CCDC.

\section{ASSOCIATED CONTENT}

\section{SI Supporting Information}

The Supporting Information is available free of charge at https://pubs.acs.org/doi/10.1021/acsomega.0c03422.

Effect of adsorbent dosage on the removal of berberine by MIL-101(Fe) (PDF)

\section{AUTHOR INFORMATION}

\section{Corresponding Author}

Ping Zeng - Chinese Research Academy of Environmental Sciences, Beijing 100012, China; (1) orcid.org/0000-00024022-2551; Email: zengping@craes.org.cn

\section{Authors}

Juan Li - Chinese Research Academy of Environmental Sciences, Beijing 100012, China

Liangjie Wang - Chinese Research Academy of Environmental Sciences, Beijing 100012, China

Yongqiang Liu - Faculty of Engineering and Physical Sciences, University of Southampton, SO17 1BJ Southampton, United Kingdom

Yan Wang - Chinese Research Academy of Environmental Sciences, Beijing 100012, China

Yizhang Zhang - Chinese Research Academy of Environmental Sciences Tianjin Branch, Tianjin 300457, China

Complete contact information is available at:

https://pubs.acs.org/10.1021/acsomega.0c03422

\section{Notes}

The authors declare no competing financial interest.

\section{ACKNOWLEDGMENTS}

This work was supported by the China Postdoctoral Science Foundation (2019M650798), the National Major Scientific and Technological Projects for Water Pollution Control and Management (2017ZX07402003), and the National Natural Science Foundation of China (41671033).

\section{REFERENCES}

(1) Wang, J.; Wang, S. Removal of pharmaceuticals and personal care products (PPCPs) from wastewater: A review. J. Environ. Manage. 2016, 182, 620-640.

(2) Li, Y.; Lu, X.; Yang, R.; Tong, W.; Xu, L.; de Bondelon, L.; Wang, H.; Zhu, J.; Ge, Q. Adsorption of berberine hydrochloride onto mesoporous carbons with tunable pore size. RSC Adv. 2016, 6, 28219-28228.

(3) Shan, Y.; Song, Y.; Liu, Y.; Liu, R.; Du, J.; Zeng, P. Adsorption of berberine by polymeric resin H103: kinetics and thermodynamics. Environ. Earth Sci. 2015, 73, 4989-4994.

(4) Liu, S.; Zhang, Y.; Zeng, P.; Wang, H.; Song, Y.; Li, J. Isolation and Characterization of a Bacterial Strain Capable of Efficient Berberine Degradation. Int. J. Environ. Res. Public Health 2019, 16, No. 646.

(5) Qin, W.; Song, Y.; Dai, Y.; Qiu, G.; Ren, M.; Zeng, P. Treatment of berberine hydrochloride pharmaceutical wastewater by $\mathrm{O}_{3} / \mathrm{UV} /$ $\mathrm{H}_{2} \mathrm{O}_{2}$ advanced oxidation process. Environ. Earth Sci. 2015, 73, 49394946.

(6) Ren, M.; Song, Y.; Xiao, S.; Zeng, P.; Peng, J. Treatment of berberine hydrochloride wastewater by using pulse electro-coagulation process with Fe electrode. Chem. Eng. J. 2011, 169, 84-90.

(7) Letašiová, S.; Jantova, S.; Cipak, L.; Muckova, M. Berberineantiproliferative activity in vitro and induction of apoptosis/necrosis of the U937 and B16 cells. Cancer Lett. 2006, 239, 254-262.

(8) Hu, Y.; Davies, G. E. Berberine inhibits adipogenesis in high-fat diet-induced obesity mice. Fitoterapia 2010, 81, 358-366.

(9) Cui, X.; Zeng, P.; Qiu, G.; Liu, Y.; Song, Y.; Xie, X.; Han, L. Pilot-scale treatment of pharmaceutical berberine wastewater by Fenton oxidation. Environ. Earth Sci. 2015, 73, 4967-4977.

(10) Komorsky-Lovrić, S. Adsorption and Reduction of Berberine at a Mercury Electrode. Electroanalysis 2000, 12, 599-604.

(11) Qiu, G.; Song, Y.-h.; Zeng, P.; Duan, L.; Xiao, S. Characterization of bacterial communities in hybrid upflow anaerobic sludge blanket (UASB)-membrane bioreactor (MBR) process for berberine antibiotic wastewater treatment. Bioresource Technol. 2013, $142,52-62$.

(12) Li, H.; Li, Y.; Li, Z.; Peng, X.; Li, Y.; Li, G.; Tan, X.; Chen, G. Preparation and adsorption behavior of berberine hydrochloride imprinted polymers by using silica gel as sacrificed support material. Appl. Surf. Sci. 2012, 258, 4314-4321. 
(13) Li, J.; Wang, M.; Liu, G.; Zhang, L.; He, Y.; Xing, X.; Qian, Z.; Zheng, J.; Xu, C. Enhanced Iodide Removal from Water by NanoSilver Modified Anion Exchanger. Ind. Eng. Chem. Res. 2018, 57, 17401-17408.

(14) Li, Y.; Fu, J.; Deng, S.; Lu, X. Optimization of mesoporous carbons for efficient adsorption of berberine hydrochloride from aqueous solutions. J. Colloid Interface Sci. 2014, 424, 104-112.

(15) Shan, Y. P.; Zeng, P.; Song, Y. H.; Gu, Y. T.; Galarneau, A.; Manero, M. H. Amino-Modified Hydrogen-Bonding Resin and its Adsorption on Berberine. Appl. Mech. Mater. 2013, 448-453, 145149.

(16) Rytwo, G.; Varman, H.; Bluvshtein, N.; König, T. N.; Mendelovits, A.; Sandler, A. Adsorption of berberine on commercial minerals. Appl. Clay Sci. 2011, 51, 43-50.

(17) Cohen, E.; Joseph, T.; Lapides, I.; Yariv, S. The adsorption of berberine by montmorillonite and thermo-XRD analysis of the organo-clay complex. Clay Miner. 2005, 40, 223-232.

(18) Zhou, H.-C. J.; Kitagawa, S. Metal-organic frameworks (MOFs). Chem. Soc. Rev. 2014, 43, 5415-5418.

(19) Van de Voorde, B.; Bueken, B.; Denayer, J.; De Vos, D. Adsorptive separation on metal-organic frameworks in the liquid phase. Chem. Soc. Rev. 2014, 43, 5766-5788.

(20) Zhu, Q. L.; Xu, Q. Metal-organic framework composites. Chem. Soc. Rev. 2014, 43, 5468-5512.

(21) He, Y.; Zhou, W.; Qian, G.; Chen, B. Methane storage in metalorganic frameworks. Chem. Soc. Rev. 2014, 43, 5657-5678.

(22) Rowsell, J. L. C.; Yaghi, O. M. Metal-organic frameworks: a new class of porous materials. Microporous Mesoporous Mater. 2004, 73, 314.

(23) Suh, M. P.; Park, H. J.; Prasad, T. K.; Lim, D. W. Hydrogen storage in metal-organic frameworks. Chem. Rev. 2012, 112, 782-835.

(24) Peterson, G. W.; Decoste, J. B.; Fatollahi-Fard, F.; Britt, D. K. Engineering UiO-66- $\mathrm{NH}_{2}$ for toxic gas removal. Ind. Eng. Chem. Res. 2014, 53, 701-707.

(25) Li, J. R.; Sculley, J.; Zhou, H. C. Metal-organic frameworks for separations. Chem. Rev. 2012, 112, 869-932.

(26) Qiu, S.; Xue, M.; Zhu, G. Metal-organic framework membranes: from synthesis to separation application. Chem. Soc. Rev. 2014, 43, 6116-6140.

(27) Zhang, T.; Lin, W. Metal-organic frameworks for artificial photosynthesis and photocatalysis. Chem. Soc. Rev. 2014, 43, 59825993.

(28) Kreno, L. E.; Leong, K.; Farha, O. K.; Allendorf, M.; Van Duyne, R. P.; Hupp, J. T. Metal-organic framework materials as chemical sensors. Chem. Rev. 2012, 112, 1105-1125.

(29) Hamedi, A.; Zarandi, M. B.; Nateghi, M. R. Highly efficient removal of dye pollutants by MIL-101 $(\mathrm{Fe})$ metal-organic framework loaded magnetic particles mediated by Poly L-Dopa. J. Environ. Chem. Eng. 2019, 7, No. 102882.

(30) Hamedi, A.; Trotta, F.; Borhani Zarandi, M.; Zanetti, M.; Caldera, F.; Anceschi, A.; Nateghi, M. R. In Situ Synthesis of MIL$100(\mathrm{Fe})$ at the Surface of Fe3O4@AC as Highly Efficient Dye Adsorbing Nanocomposite. Int. J. Mol. Sci. 2019, 20, No. 5612.

(31) Zheng, M.; Zhao, X.; Wang, K.; She, Y.; Gao, Z. Highly Efficient Removal of $\mathrm{Cr}(\mathrm{VI})$ on a Stable Metal-Organic Framework Based on Enhanced H-Bond Interaction. Ind. Eng. Chem. Res. 2019, 58, 23330-23337.

(32) Pedrazzo, A. R.; Smarra, A.; Caldera, F.; Musso, G.; Dhakar, N. K.; Cecone, C.; Hamedi, A.; Corsi, I.; Trotta, F. Eco-Friendly betacyclodextrin and Linecaps Polymers for the Removal of Heavy Metals. Polymers 2019, 11, No. 1658.

(33) Song, J. Y.; Jhung, S. H. Adsorption of pharmaceuticals and personal care products over metal-organic frameworks functionalized with hydroxyl groups: Quantitative analyses of $\mathrm{H}$-bonding in adsorption. Chem. Eng. J. 2017, 322, 366-374.

(34) Sarker, M.; Song, J. Y.; Jhung, S. H. Adsorptive removal of antiinflammatory drugs from water using graphene oxide/metal-organic framework composites. Chem. Eng. J. 2018, 335, 74-81.
(35) Hasan, Z.; Jhung, S. H. Removal of hazardous organics from water using metal-organic frameworks (MOFs): plausible mechanisms for selective adsorptions. J. Hazard. Mater. 2015, 283, 329-339.

(36) Seo, P. W.; Bhadra, B. N.; Ahmed, I.; Khan, N. A.; Jhung, S. H. Adsorptive Removal of Pharmaceuticals and Personal Care Products from Water with Functionalized Metal-organic Frameworks: Remarkable Adsorbents with Hydrogen-bonding Abilities. Sci. Rep. 2016, 6, No. 34462.

(37) Xiao, H. K.; Xiao, S. H.; Song, Y. H.; Zeng, P.; Shao, H.; Zhang, G. F.; Li, H. Study on the pretreatment and copper recovery from berberine wastewater containing copper by $\mathrm{Fe}-\mathrm{C}$ micro-electrolysis. J. Environ. Eng. Technol. 2011, 1, 15-19.

(38) Liu, Y.; Guo, J.; Xiao, Z.; Peng, D.; Song, K. Adsorption kinetics and isotherms of berberine by ZSM-5 molecular sieves from Cortex Phellodendron. React. Kinet., Mech. Catal. 2020, 129, 491-504.

(39) Xiao, S. H.; Zhang, G. F.; Song, Y. H.; Zeng, P.; Li, H. Treatment of Berberine Pharmaceutical Wastewater Containing Copper by Bipolar-electrochemical Process. J. Environ. Eng. Technol. 2011, 1, 295-299.

(40) Zhang, G. F.; Xiao, S. H.; Xiao, H. K.; Song, Y. H.; Zeng, P.; Li, H.; Shao, H. Pretreatment of Berberine Pharmaceutical Wastewater Using Electrochemical Process. Res. J. Environ. Sci. 2011, 24, 79-84.

(41) He, L.; Dong, Y.; Zheng, Y.; Jia, Q.; Shan, S.; Zhang, Y. A novel magnetic MIL-101 $(\mathrm{Fe}) / \mathrm{TiO}_{2}$ composite for photo degradation of tetracycline under solar light. J. Hazard. Mater. 2019, 361, 85-94.

(42) Yan, D.; Hu, H.; Gao, N.; Ye, J.; Ou, H. Fabrication of carbon nanotube functionalized MIL-101(Fe) for enhanced visible-light photocatalysis of ciprofloxacin in aqueous solution. Appl. Surf. Sci. 2019, 498, No. 143836.

(43) Skobelev, I. Y.; Sorokin, A. B.; Kovalenko, K. A.; Fedin, V. P.; Kholdeeva, O. A. Solvent-free allylic oxidation of alkenes with $\mathrm{O}_{2}$ mediated by Fe- and Cr-MIL-101. J. Catal. 2013, 298, 61-69.

(44) Zhang, Z.; Li, X.; Liu, B.; Zhao, Q.; Chen, G. Hexagonal microspindle of $\mathrm{NH}_{2}-\mathrm{MIL}-101(\mathrm{Fe})$ metal-organic frameworks with visible-light-induced photocatalytic activity for the degradation of toluene. RSC Adv. 2016, 6, 4289-4295.

(45) Gecgel, C.; Simsek, U. B.; Gozmen, B.; Turabik, M. Comparison of MIL-101(Fe) and amine-functionalized MIL$101(\mathrm{Fe})$ as photocatalysts for the removal of imidacloprid in aqueous solution. J. Iran. Chem. Soc. 2019, 16, 1735-1748.

(46) Li, X.; Guo, W.; Liu, Z.; Wang, R.; Liu, H. Quinone-modified $\mathrm{NH}_{2}$-MIL-101 $(\mathrm{Fe})$ composite as a redox mediator for improved degradation of bisphenol A. J. Hazard Mater. 2017, 324, 665-672.

(47) Zhang, M.-W.; Lin, K. Y. A.; Huang, C. F.; Tong, S. Enhanced degradation of toxic azo dye, amaranth, in water using Oxone catalyzed by MIL-101- $\mathrm{NH}_{2}$ under visible light irradiation. Sep. Purif. Technol. 2019, 227, No. 115632.

(48) Lu, T.; Chen, F. Multiwfn: a multifunctional wavefunction analyzer. J. Comput. Chem. 2012, 33, 580-592.

(49) Lefebvre, C.; Rubez, G.; Khartabil, H.; Boisson, J. C.; Contreras-Garcia, J.; Henon, E. Accurately extracting the signature of intermolecular interactions present in the NCI plot of the reduced density gradient versus electron density. Phys. Chem. Chem. Phys. 2017, 19, 17928-17936.

(50) Pritchard, B. P.; Altarawy, D.; Didier, B.; Gibson, T. D.; Windus, T. L. A New Basis Set Exchange: An Open, Up-to-Date Resource for the Molecular Sciences Community. J. Chem. Inf. Model. 2019, 59, 4814-4820.

(51) Feller, D. The role of databases in support of computational chemistry calculation. J. Comput. Chem. 1996, 17, 1571-1586.

(52) Schuchardt, K. L.; Didier, B. T.; Elsethagen, T.; Sun, L.; Gurumoorthi, V.; Chase, J.; Li, J.; Windus, T. L. Basis Set Exchange: A Community Database for Computational Sciences. J. Chem. Inf. Model. 2007, 47, 1045-1052.

(53) Krishnan, R.; Binkley, J. S.; Seeger, R.; Pople, J. A. Selfconsistent molecular orbital methods. XX. A basis set for correlated wave functions. J. Chem. Phys. 1980, 72, 650-654.

(54) Perdew, J. P.; Burke, K.; Ernzerhof, M. Generalized gradient approximation made simple. Phys. Rev. Lett. 1996, 77, 3865-3868. 
(55) Frisch, M. J.; Trucks, G. W.; Schlegel, H. B.; Scuseria, G. E.; Robb, M. A.; Cheeseman, J. R. S. G.; Barone, V.; Petersson, G. A.; Nakatsuji, H.; Li, X.; Caricato, M.; Marenich, A. V.; Bloino, J.; Janesko, B. G.; Gomperts, R.; Mennucci, B.; Hratchian, H. P.; Ortiz, J. V.; Izmaylov, A. F.; Sonnenberg, J. L.; Williams-Young, D.; Ding, F.; Lipparini, F.; Egidi, F.; Goings, J.; Peng, B.; Petrone, A.; Henderson, T.; Ranasinghe, D.; Zakrzewski, V. G.; Gao, J.; Rega, N.; Zheng, G.; Liang, W.; Hada, M.; Ehara, M.; Toyota, K.; Fukuda, R.; Hasegawa, J.; Ishida, M.; Nakajima, T.; Honda, Y.; Kitao, O.; Nakai, H.; Vreven, T.; Throssell, K.; Montgomery, J. A.; Peralta, J. E.; Ogliaro, F.; Bearpark, M. J.; Heyd, J. J.; Brothers, E. N.; Kudin, K. N.; Staroverov, V. N.; Keith, T. A.; Kobayashi, R.; Normand, J.; Raghavachari, K.; Rendell, A. P.; Burant, J. C.; Iyengar, S. S.; Tomasi, J.; Cossi, M.; Millam, J. M.; Klene, M.; Adamo, C.; Cammi, R.; Ochterski, J. W.; Martin, R. L.; Morokuma, K.; Farkas, O.; Foresman, J. B.; Fox, D. J.. Gaussian 16, revision B.01; Gaussian, Inc: Wallingford CT, 2016.

(56) Humphrey, W.; Dalke, A.; Schulten, K. VMD: Visual molecular dynamics. J. Mol. Graphics 1996, 14, 33-38.

(57) Chen, M.; Yan, J.; Tan, Y.; Li, Y.; Wu, Z.; Pan, L.; Liu, Y. Hydroxyalkylation of Phenol with Formaldehyde to Bisphenol $\mathrm{F}$ Catalyzed by Keggin Phosphotungstic Acid Encapsulated in MetalOrganic Frameworks MIL-100(Fe or Cr) and MIL-101(Fe or Cr). Ind. Eng. Chem. Res. 2015, 54, 11804-11813.

(58) Chen, C. Y.; Wang, C. H.; Chen, A. H. Recognition of molecularly imprinted polymers for a quaternary alkaloid of berberine. Talanta 2011, 84, 1038-1046.

(59) Li, Y.; Huang, J.; Liu, J.; Deng, S.; Lu, X. Adsorption of Berberine Hydrochloride, Ligustrazine Hydrochloride, Colchicine, and Matrine Alkaloids on Macroporous Resins. J. Chem. Eng. Data 2013, 58, 1271-1279. 